\title{
Hyperemia and impaired cerebral autoregulation in a surgical patient with diabetic ketoacidosis
}

\author{
[L'hyperémie et l'autorégulation cérébrale altérée chez un patient de chirurgie \\ atteint d'acidocétose diabétique]
}

\author{
Monica S. Vavilala MD,${ }^{*}$ Michael J. Souter MB CHB FRCA,$\uparrow$ Arthur M. Lam MD FRCPC $\ddagger$
}

Purpose: We describe cerebral hyperemia and impaired cerebral autoregulation documented with transcranial Doppler (TCD) ultrasonography in an adult patient with diabetic ketoacidosis (DKA) and sepsis presenting for surgery.

Clinical features: Middle cerebral artery flow velocity was increased relative to $\mathrm{PaCO}_{2}\left(\mathrm{Vmca} 52 \mathrm{~cm} \cdot \mathrm{sec}^{-1} ; \mathrm{PaCO}_{2} 22 \mathrm{mmHg}\right)$ and the autoregulatory index (ARI) was 0 prior to surgery. Twenty hours after admission and treatment, cerebral hyperemia resolved (Vmca $52 \mathrm{~cm} \cdot \mathrm{sec}^{-1}$; $\mathrm{PaCO}_{2} 35 \mathrm{mmHg}$ ) and cerebral autoregulation returned to normal (ARI 0.91).

Conclusion: To our knowledge, this is the first description of impaired cerebral autoregulation in adult DKA. Our observations suggest a relationship between cerebral hyperemia and impaired cerebral autoregulation in DKA.

Objectif: Décrire l'hyperémie cérébrale et l'autorégulation cérébrale altérée documentées par le Doppler transcrânien (DTC) chez un adulte atteint d'acidocétose diabétique (ACD) et de septicémie admis pour une intervention chirurgicale.

Éléments cliniques : La vitesse du flux de l'artère cérébrale moyenne a augmenté en relation avec la $\mathrm{PaCO}_{2}\left(\mathrm{Vacm}\right.$ à $52 \mathrm{~cm} \cdot \mathrm{sec}^{-1}$; $\mathrm{PaCO}_{2}$ de $22 \mathrm{mmHg}$ ) et l'index d'autorégulation (IAR) était de 0 avant l'intervention chirurgicale. Vingt heures après l'admission et le traitement, l'hyperémie cérébrale était stoppée (Vmca à $52 \mathrm{~cm} \cdot \mathrm{sec}^{-1}$; $\mathrm{PaCO}_{2}$ de $35 \mathrm{mmHg}$ ) et l'autorégulation cérébrale revenue à la normale (IAR de 0,9I).

Conclusion : Selon nous, c'est la première description d'autorégulation cérébrale altérée chez un adulte atteint d'ACD. Nos observations suggèrent une relation entre l'hyperémie cérébrale et l'autorégulation cérébrale altérée en cas d'ACD.

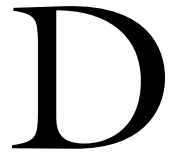

IABETIC ketoacidosis (DKA) is a common complication of insulin dependent diabetes mellitus type I (IDDM). Cerebral complications related to DKA include altered mental status, cerebral edema, cerebral infarction, coma, and brain herniation. ${ }^{1-5}$ We describe cerebral hyperemia and impaired cerebral autoregulation documented with transcranial Doppler (TCD) ultrasonography in a patient with DKA and sepsis presenting for surgery.

\section{Case report}

A 21-yr-old male presented for incision and drainage of a large posterior $s c$ abscess with surrounding cellulitis (dermatome T2-T6 distribution). The patient's past medical history was significant for a 12 -yr history of IDDM, multiple hospital admissions for DKA, oneweek history of emesis, and elevated blood glucose (range 16.7-27.8 $\mathrm{mmol} \cdot \mathrm{L}^{-1}$ ). On admission, the patient was confused and complained of back pain and thirst. His vital signs were: temperature $36^{\circ} \mathrm{C}$, pulse 140 beats. $\mathrm{min}^{-1}$, respiratory rate 40 breaths $\mathrm{min}^{-1}$, and blood pressure $120 / 80 \mathrm{mmHg}$ [mean arterial pressure (MAP) $90 \mathrm{mmHg}$ ]. Notable laboratory results included: white blood count $30 \mathrm{G} \cdot \mathrm{L}^{-1}$, hematocrit $60 \%, \mathrm{Na}^{+} 63.5 \mathrm{mmol} \cdot \mathrm{L}^{-1}, \mathrm{~K}^{+} 2.3 \mathrm{mmol} \cdot \mathrm{L}^{-1}$, $\mathrm{HCO}_{3}^{-} 4.5 \mathrm{mmol} \cdot \mathrm{L}^{-1}$, positive serum and urine ketones, and hyperglycemia $\left(22.9 \mathrm{mmol} \cdot \mathrm{L}^{-1}\right)$. Arterial blood gas on room air revealed: $\mathrm{pH} 7.24, \mathrm{PaCO}_{2} 24$ $\mathrm{mmHg}, \mathrm{PaO}_{2} 100 \mathrm{mmHg}$, and $\mathrm{HCO}_{3}-4.5 \mathrm{mmol} \cdot \mathrm{L}^{-1}$. The patient received $16 \mathrm{U}$ of $i v$ insulin $(0.05$ $\left.\mathrm{U} \cdot \mathrm{kg}^{-1} \cdot \mathrm{hr}^{-1}\right)$, and $7 \mathrm{~L}$ of normal saline $\left(1 \mathrm{~L} \cdot \mathrm{hr}^{-1}\right)$ during the seven hours prior to surgery.

From the Departments of Anesthesiology, ${ }^{*} \dagger \ddagger$ Pediatrics, ${ }^{*}$ and Neurological Surgery, $\ddagger$ University of Washington, Seattle, Washington, USA. Address correspondence to: Dr. Monica S. Vavilala, Department of Anesthesiology, Harborview Medical Center, 325 Ninth Avenue, Box 359724, Seattle, Washington 98104, USA. Phone: 206-731-3059; Fax: 206-731-8009; E-mail: vavilala@u.washington.edu Accepted for publication August 5, 2004.

Revision accepted December 10, 2004. 
TABLE Cerebral autoregulation testing at eight and $20 \mathrm{hr}$ following hospital admission

\begin{tabular}{lllllll}
\hline & Supine & Tilted & ARI & Supine & Tilted & \\
\hline $\begin{array}{l}\mathrm{PaCO}_{2} \\
(\mathrm{mmHg})\end{array}$ & 22 & & & 35 & & \\
$\begin{array}{l}\mathrm{eMAP} \\
(\mathrm{mmHg})\end{array}$ & 90 & 73 & & 90 & 73 & \\
$\begin{array}{l}\mathrm{Vmca} \\
\left(\mathrm{cm} \cdot \mathrm{sec}^{-1}\right)\end{array}$ & 52 & 41 & 0.0 & 52 & 50 & 0.91 \\
\hline
\end{tabular}

$\mathrm{ARI}=$ autoregulatory index; $\mathrm{eMAP}=$ mean arterial pressure at the external auditory meatus; $\mathrm{Vmca}=$ middle cerebral artery flow velocity. ARI $<0.4$ indicates impaired cerebral autoregulation.

On arrival at the operating room, the patient was lethargic, and complained of dizziness upon standing. His vital signs were: temperature $36^{\circ} \mathrm{C}$, pulse 100 beats $\cdot \mathrm{min}^{-1}$, respiratory rate 24 breaths $\mathrm{min}^{-1}$, and blood pressure 122/85 $\mathrm{mmHg}$ (MAP $97 \mathrm{mmHg}$ ). Laboratory results at this time (eight hours after admission) included hematocrit $45 \%, \mathrm{Na}^{+} 68 \mathrm{mmol} \cdot \mathrm{L}^{-1}, \mathrm{~K}^{+}$ $1.7 \mathrm{mmol} \cdot \mathrm{L}^{-1}, \mathrm{HCO}_{3}^{-} 4.8 \mathrm{mmol} \cdot \mathrm{L}^{-1}$, and glucose 12.4 $\mathrm{mmol} \cdot \mathrm{L}^{-1}$. Invasive arterial and central venous pressures were monitored. Arterial blood gas, while breathing room air, revealed: $\mathrm{pH} 7.24, \mathrm{PaCO}_{2} 22 \mathrm{mmHg}, \mathrm{PaO}_{2}$ $110 \mathrm{mmHg}, \mathrm{HCO}_{3}^{-} 5 \mathrm{mmol} \cdot \mathrm{L}^{-1}$.

To aid blood pressure and $\mathrm{PaCO}_{2}$ management relating to cerebral perfusion, middle cerebral artery flow velocity (Vmca) was measured using TCD ultrasonography and cerebral autoregulation was tested using the tilt test methodology, prior to induction of general anesthesia. Vmca was measured continuously using a $2-\mathrm{mHz}$ ultrasound probe. Measurements were first recorded in the supine position. The patient was then tilted $13.6 \mathrm{~cm}$ head-up to effect a $10-\mathrm{mmHg}$ decrease in MAP (assuming a decrease in MAP of 1 $\mathrm{mmHg}$ for each $1.36 \mathrm{~cm}$ increase in vertical height). Invasive MAP was measured at the level of the external auditory meatus. Cerebral autoregulation was quantified by the autoregulatory index (ARI): ${ }^{6}$

\section{ARI: $\Delta-[\mathrm{eCVR}] / \Delta \mathrm{MAP}$}

where eCVR (estimated cerebrovascular resistance) $=$ Vmca/MAP (ARI $\geq 0.4$ represents preserved cerebral autoregulation, $\mathrm{ARI}<0.4$ represents impaired autoregulation and ARI $=0$ reflects completely absent cerebral autoregulation). ${ }^{6}$ The Vmca was $52 \mathrm{~cm} \cdot \mathrm{sec}^{-1}$, suggesting cerebral hyperemia (relative to $\mathrm{PaCO}_{2}$ ) and the ARI was 0 , indicating absent autoregulation (Table).

Following preoxygenation with $100 \%$ oxygen, rapid sequence induction of general anesthesia was performed with iv etomidate $14 \mathrm{mg}$, and rocuronium $50 \mathrm{mg}$. The patient's trachea was intubated and general anesthesia was maintained using sevoflurane (endtidal concentration $1.2-2.1 \%$ ) with mechanical ventilation. The patient was placed in the prone position. MAP was maintained within $20 \%$ of baseline using iv infusion of a balanced salt solution. Arterial blood gases (30 min after incision) on $50 \% \mathrm{FIO}_{2}$, revealed a respiratory accentuation of metabolic acidosis with $\mathrm{pH} 7.19, \mathrm{PaCO}_{2} 35 \mathrm{mmHg}, \mathrm{PaO}_{2} 250$ $\mathrm{mmHg}$ and $\mathrm{HCO}_{3}-5 \mathrm{mmol} \cdot \mathrm{L}^{-1}$. Mechanical ventilation was adjusted to restore the baseline $\mathrm{PaCO}_{2}$ of 22 $\mathrm{mmHg}$ and to increase $\mathrm{pH}$. After an uneventful twohour procedure, the patient's trachea was extubated and he was admitted to the intensive care unit.

Twelve hours later $(20 \mathrm{hr}$ following hospital admission), repeat TCD examination and cerebral autoregulation testing revealed normal Vmca of $51 \mathrm{~cm} \cdot \mathrm{sec}^{-1}$ [MAP $93 \mathrm{mmHg}, \mathrm{PaCO}_{2} 35 \mathrm{mmHg}$, glucose 10.4 $\mathrm{mmol} \cdot \mathrm{L}^{-1}$, and intact cerebral autoregulation (ARI 0.91)]. The patient was discharged home on postoperative day four.

\section{Discussion}

DKA occurs in 43,000 hospital admissions per year in the 20 to $44 \mathrm{yr}$ age group ${ }^{7}$ and is the leading cause of death in diabetic patients less than 24 yr of age. ${ }^{2}$ The age adjusted death rate for DKA in the USA is 1.0 per $100,000 .{ }^{7}$ Cerebral edema occurs in $1 \%$ to $5 \%$ of DKA episodes and carries a mortality rate ranging from 45 to $80 \%$ in young patients. ${ }^{1,8,9}$ The cause of cerebral edema is controversial but an ischemic etiology has been proposed. ${ }^{1,9}$ Children with DKA may have cerebral hyperemia, with a consequent increase in intracranial pressure (ICP). ${ }^{10}$ We describe cerebral hyperemia and impaired cerebral autoregulation in an adult patient with DKA presenting for surgery.

Normal adult cerebral blood flow (CBF) averages $50 \mathrm{~mL} / 100 \mathrm{~g} \cdot \mathrm{min}^{-1}$ at a $\mathrm{PaCO}_{2}$ of $40 \mathrm{mmHg}$ and is maintained by a homeostatic process, cerebral autoregulation, whereby cerebral arterioles dilate and constrict in response to decreases and increases in MAP respectively. ${ }^{11}$ TCD ultrasonography is a noninvasive clinical tool widely used to estimate changes in CBF. Although TCD does not directly measure $\mathrm{CBF}$, changes in $\mathrm{CBF}$ correlate with changes in Vmca. ${ }^{12,13}$

In pathological states, $\mathrm{CBF}$ may be increased, decreased or unchanged relative to metabolic need ${ }^{14-17}$ and cerebral autoregulation may be impaired. ${ }^{17-19}$ The implication for patients with impaired cerebral autoregulation is that even modest hypotension or hypertension can lead to cerebral 
ischemia or hyperemia respectively. $\mathrm{CBF}$ also changes with $\mathrm{PaCO}_{2}$; hypocapnia causes cerebral vasoconstriction and hypercapnia results in vasodilation. This $\mathrm{CO}_{2}$ response can be altered physiologically with either a decrease in sensitivity to $\mathrm{CO}_{2}$ or by a shift of the $\mathrm{CO}_{2}$ response curve in response to changes in acid-base metabolism. Hyperemia can, subsequently, lead to vasogenic cerebral edema and increased ICP. Additionally, $\mathrm{PaCO}_{2}>55 \mathrm{mmHg}$ has been shown to impair cerebral autoregulation in healthy adults ${ }^{20}$ rendering $\mathrm{CBF}$ dependent on MAP. The presence of hyperemia has also been associated with impaired cerebral autoregulation in brain-injured patients. ${ }^{17}$

In the only report of TCD assessment of intracranial hemodynamics in DKA, Hoffman and colleagues reported vasoparalysis and suggested the presence of increased ICP that resolved when $\mathrm{PaCO}_{2}$ returned to normal. In their series of five children nine to $13.5 \mathrm{yr}$, TCD measurements were made prior to treatment, at six, 24, $48 \mathrm{hr}$ of treatment and on day six of admission. ${ }^{10}$ Although the cerebrovascular changes in DKA have not yet been clearly elucidated, and the effect of DKA on cerebral autoregulatory capacity and $\mathrm{CO}_{2}$ reactivity in adults is largely unknown, our observation of vasoparalysis and cerebral hyperemia support the findings of Hoffman et al. ${ }^{10}$ Most recently, Glaser and colleagues reported increased apparent diffusion coefficients on magnetic resonance imaging in children with DKA, also suggesting a vasogenic mechanism for the development of cerebral edema. ${ }^{21}$

Since hyperventilation decreases CBF, we were concerned about intraoperative cerebral ischemia, and considered increasing $\mathrm{PaCO}_{2}$ to prevent cerebral ischemia. However, a decrease in alveolar minute ventilation could increase $\mathrm{PaCO}_{2}$ and $\mathrm{CBF}$ and worsen the patient's acidosis. Hypotension in the context of disordered autoregulation could predispose to cerebral ischemia, but paradoxically, volume resuscitation may itself result in cerebral edema. To solve this clinical dilemma and to guide the ventilation and hemodynamic management of this patient, we measured Vmca and examined cerebral autoregulation preoperatively. Unexpectedly, Vmca was within normal physiologic range but high relative to the low $\mathrm{PaCO}_{2}$. Correction of this hypocarbia might have increased $\mathrm{CBF}$ and cerebral blood volume, with an increase in ICP and risk of edema, and we therefore maintained the pre-existing hypocarbia. Impaired autoregulation mandated tightly controlled MAP, and was accomplished satisfactorily with fluid administration. Given the abnormal perioperative observations, we re-examined Vmca and cerebral autoregulation during recovery. Twenty hours following admission, the patient's metabolic condition improved, hyperemia resolved (Vmca $51 \mathrm{~cm} \cdot \mathrm{sec}^{-1}, \mathrm{PaCO}_{2} 35 \mathrm{mmHg}$ ) and cerebral autoregulation normalized.

These observations suggest a metabolic etiology for this patient's cerebrovascular abnormalities. Classically metabolic acidosis is considered of minor relevance in determining CBF but the combination of acidemia, and hyperglycemia may override the vasoconstrictive effect of hyperventilation and cause hyperemia. ${ }^{10}$ In liver transplantation, metabolic acidosis has been shown to impair cerebral autoregulation. ${ }^{22}$

Clinically apparent cerebral edema is relatively infrequent but several studies suggest subclinical cerebral edema to be common. ${ }^{23,24}$ Proposed mechanisms for cerebral edema include osmotic disequilibrium between brain and plasma, intracellular acidosis, overhydration and hyponatremia, and cerebral ischemia. ${ }^{25}$ Suspected clinical risk factors include high admission serum urea nitrogen concentrations, bicarbonate treatment, metabolic acidosis and hypocapnia. ${ }^{8,26,27}$ Although this patient did not have clinical evidence of cerebral edema, no imaging studies were performed and we cannot exclude its presence. Our physiologic observations are important because they suggest that cerebrovascular changes in DKA may derive from cerebral hyperemia rather than cerebral ischemia. It can be theorized that cerebral ischemia is a consequence of hyperemia related cerebral edema in DKA.

In conclusion, to our knowledge, this is the first description of impaired cerebral autoregulation in an adult patient with DKA. Our observation suggests a relationship between cerebral hyperemia and impaired cerebral autoregulation in DKA. These changes may be related to DKA related metabolic alterations and may be of importance to clinicians managing patients with DKA. The presence of DKA in the surgical patient may constitute an indication for TCD ultrasonography to exclude impaired cerebral autoregulation during the perioperative period.

\section{References}

1 Glaser N. Cerebral edema in children with diabetic ketoacidosis. Curr Diab Rep 2001; 1: 41-6.

2 Dunger DB, Sperling MA, Acerini CL, et al. European Society for Paediatric Endocrinology. Lawson Wilkins Pediatric Endocrine Society. European Society for Paediatric Endocrinology/Lawson Wilkins Pediatric Endocrine Society consensus statement on diabetic ketoacidosis in children and adolescents. Pediatrics 2004; 113: el33-40.

3 Brown TB. Cerebral oedema in childhood diabetic ketoacidosis: is treatment a factor? Emerg Med J 2004; 21: $141-4$. 
4 Ertl-Wagner B, Jansen O, Schwab S, Sartor K. Bilateral basal ganglion haemorrhage in diabetic ketoacidotic coma: case report. Neuroradiology 1999; 41: 670-3.

5 Roe TF, Crawford TO, Huff KR, Costin G, Kaufman $F R$, Nelson MD Jr. Brain infarction in children with diabetic ketoacidosis. J Diabetes Complications 1996; 10: 100-8.

6 Strebel S, Lam AM, Matta B, Mayberg TS, Aaslid R, Newell DW. Dynamic and static cerebral autoregulation during isoflurane, desflurane, and propofol anesthesia. Anesthesiology 1995; 83: 66-76.

7 Center for Disease Statistics Surveillance. The Public Health Burden of Diabetes Mellitus in the United States. 1999. http://www.cdc.gov/diabetes/statistics/survl99/chapl/ketoacidosis.htm. Accessed April 6, 2004.

8 Glaser N, Barnett P, McCaslin I, et al. The Pediatric Emergency Medicine Collaborative Research Committee of the American Academy of Pediatrics. Risk factors for cerebral edema in children with diabetic ketoacidosis. N Eng J Med 2001; 344: 264-9.

9 Marcin JP, Glaser N, Barnett P, et al. American Academy of Pediatrics. The Pediatric Emergency Medicine Collaborative Research Committee. Factors associated with adverse outcomes in children with diabetic ketoacidosis-related cerebral edema. J Pediatr 2002; 141: 754-6.

10 Hoffman WH, Pluta RM, Fisher AQ, Wagner MB, Yanovski JA. Transcranial Doppler ultrasound assessment of intracranial hemodynamics in children with diabetic ketoacidosis. J Clin Ultrasound 1995; 23: 517-23.

11 Paulson OB, Strandgaard S, Edvinson L. Cerebral autoregulation. Cerebrovasc Brain Metab Rev 1990; 2: 161-92.

12 Larsen FS, Olsen KS, Hansen BA, Paulson OB, Knudsen $G M$. Transcranial Doppler is valid for determination of the lower limit of cerebral blood flow autoregulation. Stroke 1994; 25: 1985-8.

13 Hughson RL, Edwards MR, O'Leary DD, Shoemaker $J K$. Critical analysis of cerebrovascular autoregulation during repeated head-up tilt. Stroke 2001; 32: 2403-8.

14 Bruce DA, Alavi A, Bilaniuk L, Dolinskas C, Obrist W, Uzzell B. Diffuse cerebral swelling following head injuries in children: the syndrome of "malignant brain edema”. J Neurosurg 1981; 54: 170-8.

15 Bouma GJ, Muizelaar JP, Fatouros P. Pathogenesis of traumatic brain swelling: role of cerebral blood volume. Acta Neurochir Suppl (Wein) 1998; 71: 272-5.

16 Zwienenberg $M$, Muizelaar JP. Severe pediatric head injury: the role of hyperemia revisited. J Neurotrauma 1999; 16: 937-43.

17 Vavilala MS, Lee LA, Boddu K, et al. Cerebral autoregulation in pediatric traumatic brain injury. Pediatr Crit
Care Med 2004; 5: 257-63.

18 Junger EC, Newell DW, Grant GA, et al. Cerebral autoregulation following minor head injury. J Neurosurg 1997; 86: 425-32.

19 Sabuquillo J, Munar F, Baguena M, Poca MA, Pedraza $S$, Rodriguez-Baeza A. Evaluation of cerebrovascular $\mathrm{CO}_{2}$-reactivity and autoregulation in patients with post-traumatic diffuse brain swelling (diffuse injury III). Acta Neurochir Suppl (wien) 1998; 71: 233-6.

20 McCulloch TJ, Visco E, Lam AM. Graded hypercapnia and cerebral autoregulation during sevoflurane or propofol anesthesia. Anesthesiology 2000; 93: 1205-9.

21 Glaser NS, Wootton-Gorges SL, Marcin JP, et al. Mechanism of cerebral edema in children with diabetic ketoacidosis. J Pediatr 2004; 145: 164-71.

22 Doblar DD, Frenette L, Poplawski S, et al. Middle cerebral artery transcranial Doppler velocity monitoring during orthotopic liver transplantation: changes at reperfusion - a report of six cases. J Clin Anesth 1993; 5: 479-85.

23 Krane EJ, Rockoff MA, Wallman JK, Wolfsdorf JI. Subclinical brain swelling in children during treatment of diabetic ketoacidosis. N Engl J Med 1985; 312: 1147-51.

24 Hoffman WH, Steinhart CM, El-Gammal T, Steele S, Cuadrado AR, Morse PK. Cranial CT in children and adolescents with diabetic ketoacidosis. AJNR Am J Neuroradiol 1988; 9: 733-9.

25 Silver SM, Clark EC, Schroeder BM, Sterns RH. Pathogenesis of cerebral edema after treatment of diabetic ketoacidosis. Kidney Int 1997; 51: 1237-44.

26 Mahoney CP, Vlcek BW, DelAguila M. Risk factors for developing brain herniation during diabetic ketoacidosis. Pediatr Neurol 1999; 21: 721-7.

27 Edge JA. Cerebral oedema during treatment of diabetic ketoacidosis: are we any nearer finding a cause? Diabetes Metab Res Rev 2000; 16: 316-24. 